\title{
Improving the Performance of Children School Meal using Meal Report at Kindergarten School in Indonesia: A Quasi-Experimental Study
}

\author{
Haripin Togap Sinaga ${ }^{1}$, Nurman Achmad ${ }^{2 *}$, Yessi Alza ${ }^{3}$, Berlin Sitanggang ${ }^{1}$ \\ ${ }^{1}$ Department of Nutrition, Politeknik Kesehatan Medan, Medan, Indonesia; ${ }^{2}$ Department of Anthropology, Universitas Sumatera \\ Utara, Medan, Indonesia; ${ }^{3}$ Department of Nutrition, Politeknik Kesehatan Riau, Pekanbaru, Indonesia
}

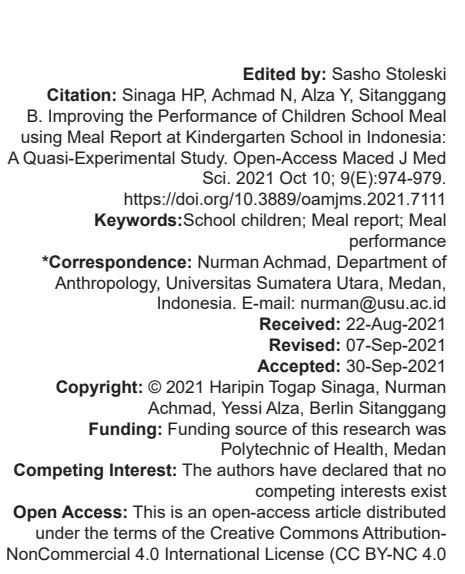

Abstract

BACKGROUND: Kindergarten children are prone to be stunted. Currently, most kindergarten school run schoo meal program.

AIM: The aim of the study was to assess the effect of school meal report on the meal performance.

METHODS: The study was a Quasi Experiment. Four kindergarten schools were selected; two schools as intervention study and the other two schools as the control group. We enrolled 106 mothers. There were five items of food performance to be scored from 6 to 10. While children in the control group were suggested to bring meals every day without a school meal report.

RESULTS: At baseline the range score of five items was not significantly different, the average score was $7.15 \pm 0.21$ vs $7.09 \pm 0.18 ; p>.05$ in the intervention group and control group respectively. However, at end-line the scores mea performance in the study group was significantly improve and made it meaningfully different than in the control group $(8.94 \pm 0.31$ vs $7.52 \pm 0.40 ; p<.05)$. The meal performance in both groups started at low performance. However, in study group at week four the scores gradually improved to the best performance at week eight till week twelve, while meal performance children in control group had a low performance.

CONCLUSION: Meal report is effective in improving meal performance of kindergarten children. Future studies need to find the effect of school meal reports on nutritional status and frequency of sickness.

\section{Introduction}

Much attention has been given to the nutritional status of pre-school children because they are prone to stunting. At present, one out of three children is suffering from malnutrition [1]. The challenging issue for kindergarten children is healthy school meal to main health and nutrition status [2] and to produce nutritionally school meal model [3], hence, less vegetable and fruit intake during childhood play an important role presence of stunting [4] and cardiovascular disease [5].

At present, most kindergarten schools run school meal programs. The objective of the school meal program is to promote healthy food behavior [2], be part of a healthy lifestyle to improve cognitive function and well-being [6]. The facts of the presence of feeding school affected stunting prevalence of schoolchildren, body weight and cognitive performance have been proved [6], [7].

However, several studies reported that the food consumption of children did not meet the nutritional suggestion. In Indonesia, the intake of vegetables and fruits of children is very low, only 50-80 g/day [8] Similar results come from a study in a developed country, children consume vegetables and fruit only once daily and less vitamin and minerals [9]. The World Health Organization recommends children and adolescents to consume at least $200 \mathrm{~g}$ vegetables and fruits daily [10], [11].

School meal programs could be the solution to that nutritional problem in children. However, school meals program must be able to achieve better nutrition, better concentration, better school performance, healthier children and smarter [5], [11], [12].

Based on these studies, we concluded that the quality needs to put in high concern for school meal performance.

In this study, we introduce school meal report book as media communication between teacher and mother. This book contains five items of meal performance and scores. The five items are: (1) types of foods, (2) way of processing, (3) the way of serving, (4) food consumed, and (5) type of meal boxes. Each item has value from 6.0 to 10.0. The higher the score means the better performance. This approach is according to achievement motivation theory and risk communication. The theory mentions that most individuals hope for 
success and fear failure [12], and risk information can improve mothers' risk perception [13].

In Indonesia, more than 200,000 kindergarten school with around 10 million students taught by more than 750,000 teachers. These can be a potential target in the application of the school meal report program. The objective of the study was to assess the effect of meal reports on school meal performance. The result of this study can be a contrasting model for administering nutrition education for mothers and teachers of kindergarten schools.

\section{Methods}

The study was a quasi-experimental study, we selected four kindergarten schools purposively; two as intervention location and the other two schools as control study. Two kindergarten schools were in Lubuk Pakam, North Sumatera Province and the other two schools were in Pekanbaru, Riau Province.

A total of 106 mothers with 106 children aged 4-6 years old involved as respondents and samples; 53 mothers in intervention and 53 in the control group. The schools' selection according to the following criteria; the ratio of teacher to student was 1 and 10 , permanent learning classroom, running school meal program, and complete school administration. The study was conducted from April until July 2018.

\section{PRA intervention}

\section{Designing school meal report}

The idea of designing and using meal report for kindergarten students was based on the evaluation of the existing school meal program. More than half portion of the school meal not be eaten by children. Then, observing daily school and making scores and grades are part of teachers activities in kindergarten schools.

The school meal report consists of ten pages, at page two was presented explanation how to use the meal report. Scoring sheets are four pages and the other pages present nutritional information including samples of attractive school meals.

There are five items of food performance need to score; (1) types of food, (2) way of processing, (3) way of serving, (4) consumed, and (5) meal box. Each item had score range from 6.0 to 10.0 .

In addition to this meal report, a monitoring book also provided for teachers to score children's daily meals. Before use this media in research, a trial had been done in another kindergarten school. Previously, there were seven items recorded in the school meal report, however, two items; drink and nutrient content were excluded.

\section{Intervention}

The flowchart of intervention activities was presented in Figure 1. The flowchart showed four steps of intervention. The intervention was started with distribution of meal report, step two was to do daily scoring, step three was evaluation of weekly scoring and the last step was send feed back to mothers.

Each mother in the intervention group was given a school meal report book. Three times nutrition education sessions were delivered to mothers and teachers. Lessons focused on proper nutrition for school children, nutritious and attractive food, and the function of the meal report book. The intervention activities took place at school and also at home when the enumerator visited the children's house. Every morning teachers do daily monitoring to score children's meals. Every Friday, teachers put the average scores of the five items into the meal report book and submit the meal report to mothers. For children who got low scores (between 6.0 and 7.9) teachers write notes "please improve the food performance" and children who have high scores (between 8.0 and 10.0) teachers put notes "keep the good performance of children meal". Then every Monday, mothers sent back the meal report book to teachers. While teachers in the control group did scoring against the five items but not to share the score with mothers, but the teachers were guided on how to fill monitoring books and school meal reports.

Three sessions of nutrition education and counseling conducted during the intervention. The first and second sessions took part in class while the third session was done at home. Mothers in intervention group were informed the trend of scores of children meals. The duration of intervention took place for twelve weeks from April until July 2018.

Informed consent was obtained from mothers who were willing to take part in the study. Ethical approval of the study was obtained from the Health Research Ethics Committee, Polytechnic of Health Medan.

Daily scores were collected into the monitoring book then the average scores are entered into the school meal report sheet. Data entry and analysis were done using the Statistical Package for the Social Sciences (SPSS) version 17 software. Descriptive statistics and t-test analyses were done by comparing

Table 1: Baseline and end line of meal score in intervention and control study

\begin{tabular}{llll}
\hline Time of study & \multicolumn{2}{l}{ The score of meal performance } & p-value \\
\cline { 2 - 3 } & Intervention & Control & \\
\cline { 2 - 3 } & Average \pm SD & Average \pm SD & \\
\hline Baseline & $7.15 \pm 0.21$ & $7.09 \pm 0.18$ & 0.31 \\
End line & $8.94 \pm 0.31$ & $7.52 \pm 0.40$ & 0.00 \\
\hline
\end{tabular}


the mean and standard deviation (SD) scores between the intervention and control groups.

\section{Sample size, data collection, and processing}

Sample size used this formula, $n=\{Z 1$ $\alpha / 2 \sqrt{ } 2 P Q+Z 1-\beta \sqrt{ }[P 1(1-P 1)+P 2(1-P 2)]\} 2 /(P 1-P 2) 2$. Then, a $10 \%$ was added for dropout possibility in each group made the total sample size became 55 persons. Based on this calculation, 50-55 mothers were recruited from each location of study.

Characteristics of children and parents were taken using questionnaires. The characteristics data include children age, sex, weight and height, parents education and occupation, family income. These data were presented in distribution frequency and a paired t-test was taken to analyze the equivalence of the two groups.

The five items of food performance were; (1) types of food, (2) way of processing, (3) way of serving, (4) food consumed, and (5) meal box. Each item was considered to score of 6 or 8 or 10 depends on the operational definition in Table 1. Score 6.0 7.5 means low performance, score 7.6-8.5 = good performance, and score 8.6-10.0 = best performance. Then, the scores of each item were used in analyzing.

The scores that have been collected were recorded in a logbook. The average scores then entered manually in a sheet. Analysis was done using SPSS version 17 software. Descriptive statistics and t-independent test analyses were done by comparing the mean and SD scores between intervention and control groups.

\section{Results}

Table 1 presents the composite score at baseline and end line and Table 2 shows the average scores of five items of meal performance between study and control group. It can be seen that at baseline, the school meal performance between the study group and the control was not significantly different, $p=0.03$. The scores of both groups $(7.15 \pm 0.21$ vs. $7.09 \pm 0.18)$ indicated that the meal performance was low (score 6.0-7.5). Then, Table 2 strengthened the findings of

Table 2: Average ( $\pm S D)$ scores of five items of meal performance in intervention and control group at end line

\begin{tabular}{llll}
\hline $\begin{array}{llll}\text { Item of } \\
\text { performances }\end{array}$ & Study group & & Control group \\
\cline { 2 - 3 } & Score \pm SD & Score \pm SD & ??? \\
\hline Types of food & $8.62 \pm 0.29$ & $7.21 \pm 0.43$ & 0.00 \\
Way of serving & $9.16 \pm 0.42$ & $8.11 \pm 0.65$ & 0.01 \\
Way of processing & $8.99 \pm 0.43$ & $7.17 \pm 0.45$ & 0.00 \\
Food consumed & $9.12 \pm 0.31$ & $7.87 \pm 0.41$ & 0.00 \\
Meal box & $8.89 \pm 0.41$ & $8.02 \pm 0.42$ & 0.02 \\
\hline
\end{tabular}

Table 1. It shows that among the five items, none of the variables was not significantly different, all $p<0.05$. The way of serving and food consumed had higher scores than the other three variables ( $>9.0$ in the study group and $>8.0$ in the control group).

The average score of the five items of meal performance started from score 7.2 and slightly increased at weeks 2 and 3 (7.6 and 7.9). On contrary, in the control group, the scores decreased slightly from 7.2 to 7.0. When entering week $4-$ week 6 , the meal performance in the study area increased meaningfully by 1.6 point (from 7.9 to 9.5 ), concurrently in the control group went up only 1.0 point (from 7.1 to 8.1 ). However, in the next 1 week, the scores in both groups went down 0.6 point and 1.0 at the intervention group and control group, respectively. At week 8 , the trend of score went up in both groups, from 8.9 to 9.9 in the intervention group and from 7.1 to 7.8 in the control group and then the trend line stay stagnant until week 12 (score 9.9 and 7.8 in study group and control group, respectively).

\section{Discussion}

\section{Using scores in school meal report}

This study proved that using school meal report effectively improved the meal performance of kindergarten students. This achievement can be explained by the relation between scoring system and mothers' motivation. When mothers were informed that their children getting low scores (6.0-7.5) and receive suggestion notes from the teachers, mothers became feel guilty because they did not practice their cognitive ability for their children.

In this process, achievement motivation theory and risk communication method properly work. These findings according to Brunstein stated that most individuals hope for success and fear of failure. It can be assumed that mother has fear if her child fails in achieving better performance for his school meal [12].

Numbers and scoring systems are frequently used to motivate patients to follow doctor's suggestions, and currently, numbers, ratios, and percentages are used in public health [13], [14], [15].

The information exchange between teachers and mothers through meal reports took place for three weeks. Teachers send feedback to mothers and mothers send response to teachers. This intervention process might play an important role in improving mothers nutritional behavior. It is in line with the study by Verbeke, found that communication and information markedly affected food consumers [15].

This study proved that the involvement the headmaster, teachers, mothers, and students are 


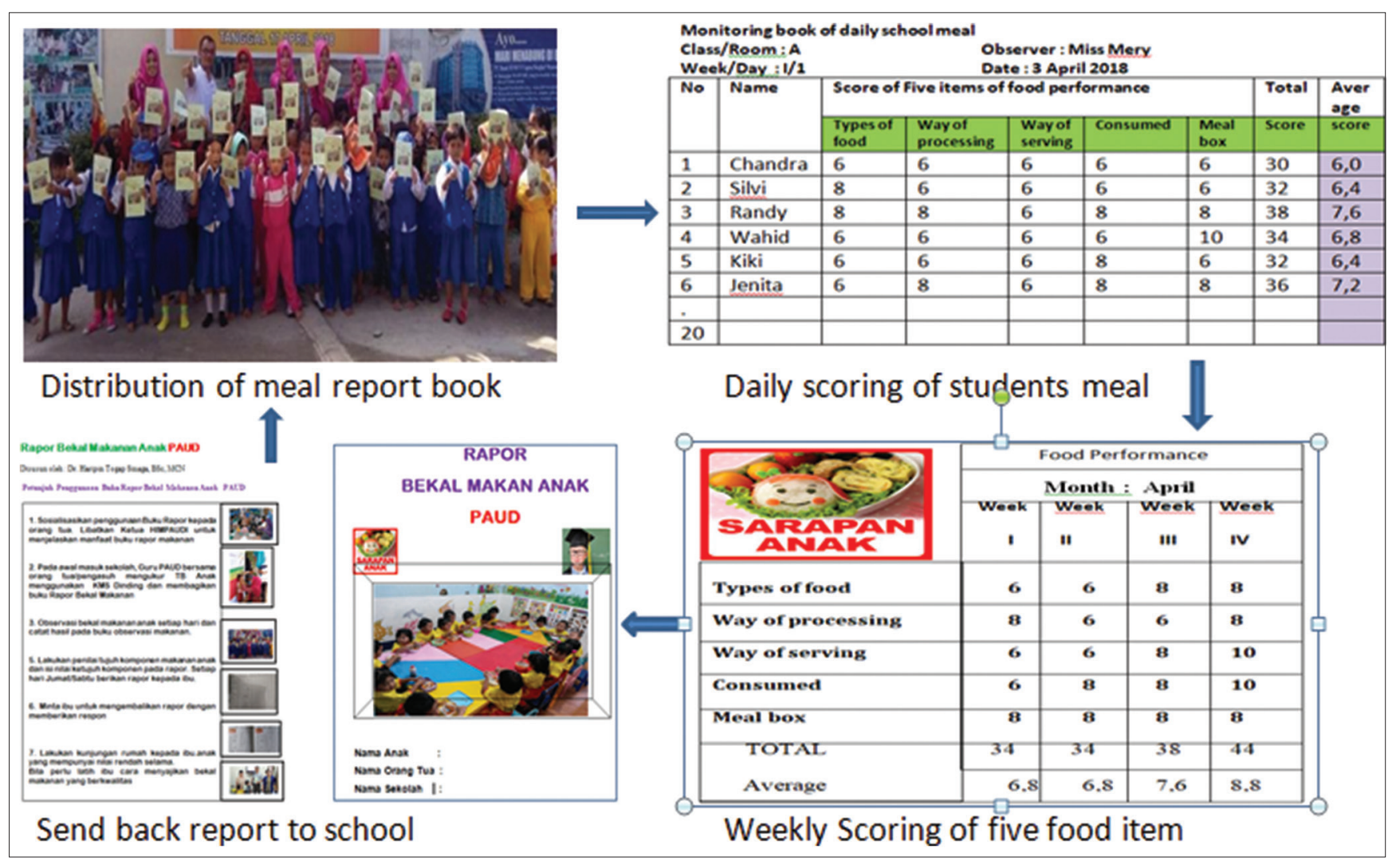

Figure 1: Flowchart of intervention

crucial in such school-based study. The presence of school meal report in fact enhances the school accreditation. What we have done is accordingly to study conducted by Rodrigo. He suggested that the ideal school-based nutrition teachers [16].

The three sessions of nutrition education in this study might have affected the mothers nutritional behavior in particular in preparing school meal for their children. This finding was in line with several studies proved that nutrition education can change someone nutritional behaviors [17], fast food choice by adolescents [10], and nutrition status of children [18].

\section{Five items of meal performance}

This study determined that to have good meal performance, the school meal should contain foods such as rice, fish, vegetable, fruits, and variation. These types of food contain carbohydrates, protein, vitamin, and minerals that needed by the body. The way of processing and serving should not monotonic. Children will get bored to eat food if they only eat fried rice or fried noodles. In serving in meal boxes, garnishing is needed because it will attract children to eat more food. The more the children consume food it will meet the minimum intake of calories $200-300$ calories. Then, the criteria of meal boxes should heat resistant to prevent children from food-borne disease.

Most researches on meal for children used those criteria. Children require micronutrient, the intake should meet the dietary recommendation [6], [19], [20], energy source of meal should meet $15-30 \%$ of total daily needs [21] and food safety for children [22]. Fung stated that foodborne disease can emerge from media used such as meal boxes, plastic matters, and the Indonesian Food and Drug Monitoring Board prohibited to use plastic bag for children food.

\section{The duration to take the effect of intervention}

As shown in Figure 2, the effect of intervention took at least 4 weeks after the meal report send to mothers. During these 4 weeks, teachers and mothers have been maintaining a communication through the meal report media. Teachers write notes to mothers and mothers send the response by changing food types, variations of serving of children meal. However, in the next 2 weeks, there was a downtrend. It can be assumed that it need more time is not easy to change mothers' behavior.

At week 9 until week 12, the scores of meal performance increased to the best performance. All items got scores $>8.0$. This achievement might be because of the method used in which mothers in intervention study were put into a group while in control study the mothers was individually. Similar study found in the study conducted by Steinmetz,et.al. They found that grouping is more successful than individually [23]. 


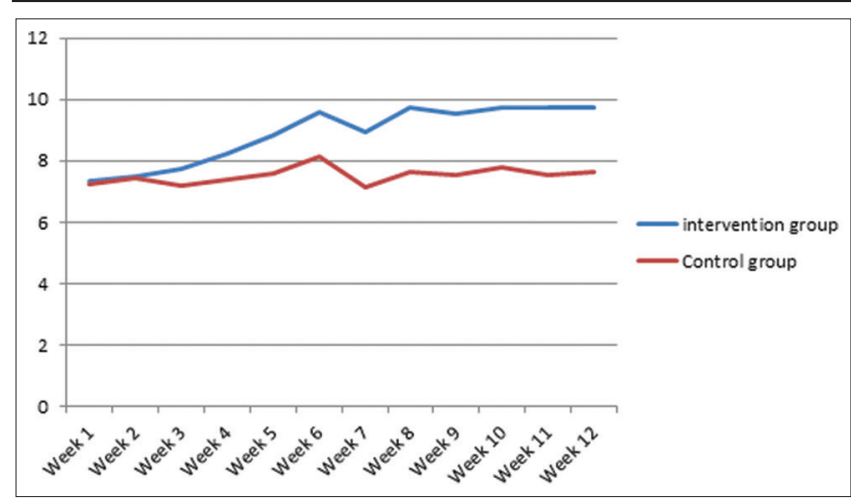

Figure 2: Trend of average score of food performance during 12 weeks of study

\section{Implication of findings}

The implication of this research, kindergarten school should consider two main things; first, the burden of teachers and mothers to do daily food observation and preparing healthy meals for children and the benefit of the application school meal report to get better accreditation and healthy children.

\section{Limitations and strengths}

This study has some limitations. First of all, potential risk may arise from a lack of information of family income and children breakfast at home. Children who did not consume food at school could be because he is not hungry at school mealtime. Second, we did not count energy source, energy intake, and number of vegetables and fruit consumed.

The strength of this manuscript, to our knowledge that giving scores to five items of school meal, assist teacher and mothers evaluate the meal performance. Previously, we were doubt of mothers to interpret scores and teachers suggestions. It is because mothers put a high belief that what teachers suggest is best for their children.

\section{Conclusion}

Using scoring system is effective in improving the performance of school meal. Active communication between teachers and mothers through meal report has changed mothers nutritional behavior. Mothers became aware the importance of meal performance of their children. The successful of intervention effect of intervention is highly depending on the interest of school masters and role of teachers.

This study concluded that meal report book can be an instrumental value for school, children, and for parents.
Future studies need to more schools and respondents and evaluate the composition of school meal and to produce the nutritionally school meal model.

\section{Acknowledgment}

The authors express gratitude to evaluators of intervention at earlier stage and proposal reviewers. We acknowledge Ida Nurhayati (Director of Polytechnic of Health, Medan), Mangapul Banjarnahor (Chairman, Nutrition Department, Polytechnic of Health, Riau). We thanked to principal of kindergarten schools for providing secondary data and to enumerators for their hard works during the study.

\section{References}

1. Gulati JK. Child malnutrition: Trends and issues. Anthropologist. 2010;12(2):131-40.

2. Oostindjer $M$, Aschemann-Witzel J, Wang $Q$, Skuland $A E$, Egelandsdal B, Amdam GV, et al. Are school meals a viable and sustainable tool to improve the healthiness and sustainability of children's diet and food consumption? A crossnational comparative perspective. Crit Rev Food Sci Nutr. 2017;57(18):3942-58. https://doi.org/10.1080/10408398.2016.1 197180

PMid:27712088

3. Tikkanen I. Nutritionally balanced school meal model for a comprehensive school. Br Food J. 2011;113(2):222-33. https:// doi.org/10.1108/00070701111105312

4. van Stuijvenberg ME, Nel J, Schoeman SE, Lombard CJ, du Plessis LM, Dhansay MA. Low intake of calcium and Vitamin $D$, but not zinc, iron or Vitamin $A$, is associated with stunting in 2- to 5-year-old children. Nutrition. 2015;31(6):841-6. https://doi.org/10.1016/j.nut.2014.12.011

PMid:25933491

5. Sorensen LB, Dyssegaard CB, Damsgaard CT, Petersen RA, Dalskov SM, Hjorth MF, et al. The effects of Nordic school meals on concentration and school performance in 8- to 11-year-old children in the OPUS School Meal Study: A cluster-randomised, controlled, cross-over trial. $\mathrm{Br} \mathrm{J}$ Nutr. 2015;113(8):1280-91. https://doi.org/10.1017/s0007114515000033 PMid:25791747

6. Rampersaud GC, Pereira MA, Girard BL, Adams J, Metzl JD. Breakfast habits, nutritional status, body weight, and academic performance in children and adolescents. J Am Diet Assoc. 2005;105(5):743-60. https://doi.org/10.1016/j.jada.2005.02.007 PMid: 15883552

7. Kwabla MP, Gyan C, Zotor F. Nutritional status of in-school children and its associated factors in Denkyembour district, Eastern region, Ghana: Comparing schools with feeding and non-school feeding policies. Nutr J. 2018;17(1):1-8. https://doi. org/10.1186/s12937-018-0321-6

8. Hermina $\mathrm{H}$. Intake of vegetables and fruits of Indonesian people in balance nutrition program: Individula food survey 2014. Bul 
Penelitian Kesehatan. 2016;44(3):4-10.

9. Sum TA. The importance teaching children for school children. J Smart Paud. 2019;2(1):43-6.

10. Allen KN, Taylor JS, Kuiper R. Effectiveness of nutrition education on fast food choices in adolescents. J Sch Nurs. 2007;23(6):337-41.

PMid: 18052519

11. Anderson ML, Gallagher J, Ramirez RitchieE. School meal quality and academic performance. J Public Econ. 2018;168:81- 93. https://doi.org/10.1016/j.jpubeco.2018.09.013.

12. Brunstein JC, Heckhausen H. Achievement motivation. In: Motivation and Action. $3^{\text {rd }}$ ed. Berlin, Germany: Springer; 2018. https://doi.org/10.1007/978-3-319-65094-4_6

13. Gerrard M, Gibbons FX, Reis-Bergan M. The effect of risk communication on risk perceptions: The significance of individual differences. J Natl Cancer Inst Monogr. 1999;50011(25):94- 100. https://doi.org/10.1093/oxfordjournals.jncimonographs.a024217 PMid:10854464

14. Schapira MM, Fletcher KE, Ganschow PS, Walker CM, Tyler B, Del Pozo S, et al. The meaning of numbers in health: Exploring health numeracy in a mexican-american population. J Gen Intern Med. 2011;26(7):705-11. https://doi.org/10.1007/ s11606-011-1645-5

PMid:21336671

15. Verbeke W. Impact of communication on consumers' food choices. Proc Nutr Soc. 2008;67(3):281-8.

PMid:18498672

16. Pérez-Rodrigo C, Aranceta J. Nutrition education in schools: Experiences and challenges. Eur J Clin Nutr. 2003;57(1):S82-5. https://doi.org/10.1038/sj.ejcn.1601824

PMid:12947462
17. Kulwa KB, Verstraeten $R$, Bouckaert KP, Mamiro PS, Kolsteren PW, Lachat $C$. Effectiveness of a nutrition education package in improving feeding practices, dietary adequacy and growth of infants and young children in rural Tanzania: Rationale, design and methods of a cluster randomised trial. BMC Public Health. 2014;14:1077. https:// doi. org/10.1186/1471-2458-14-1077

PMid:25318980

18. Majamanda J, Maureen D, Munkhondia TM, Carrier J. The effectiveness of community-based nutrition education on the nutrition status of under-five children in developing countries. A systematic review. Malawi Med J. 2014;26(4):115-8.

PMid:26167260

19. Viteri FE, Gonzalez H. Adverse outcomes of poor micronutrient status in childhood and adolescence. Nutr Rev. 2002;60(5):S77-83. https://doi. org/10.1301/00296640260130795 PMid: 12035865

20. Giménez-Legarre N, Miguel-Berges ML, Flores-Barrantes $P$, Santaliestra-Pasías AM, Moreno LA. Breakfast characteristics and its association with daily micronutrients intake in children and adolescents-a systematic review and meta-analysis. Nutrients. 2020;12(10):1-23. https://doi.org/10.3390/nu12103201 PMid:33092061

21. Perdana F, Hardinsyah $\mathrm{H}$. Analisys of type and nutrient quality of breakfast of Indonesian children. J Gizi dan Pangan. 2013;8(1):39.

22. Fung $\mathrm{F}$, Wang HS, Menon S. Food safety in the $21^{\text {st }}$ century Biomed J. 2018;41(2):88-95.

23. Steinmetz HM. How efective are behavior change intervention based on the theory of planned behavior. Zeitschr Psychol. 2016;224:216-33. 